\title{
Remote sensing mapping of the rice field and vegetal cover and the impacts of soil factors on herbaceous in the sub-watershed of Boutolate (lower Casamance, Senegal)
}

\author{
Hyacinthe. Sambou ${ }^{1,2}$, Bienvenu. Sambou ${ }^{1}$, Amadou. Tahirou. Diaw ${ }^{2}$, Cheikh. Mbow ${ }^{1,2,3}$, \\ Vieux. Boukhaly. Traore ${ }^{4}$ \\ ${ }^{1}$ Institut des Sciences de l'Environnement, Faculté des Sciences et Techniques, Université Cheikh Anta Diop de Dakar, Sénégal. BP 5005 \\ Dakar-Fann \\ ${ }^{2}$ Laboratoire d'Enseignement et de Recherche en Géomatique Ecole Supérieure Polytechnique, Université Cheikh Anta Diop, Sénégal., \\ Dakar-Fann \\ ${ }^{3}$ Agroforestry Centre (ICRAF), Nairobi Kenya \\ ${ }^{4}$ Laboratoire d'Hydraulique et de Mécanique des Fluides, Université Cheikh Anta Diop de Dakar, Sénégal. BP 5005 Dakar-Fann
}

\author{
Email address: \\ Sambouzeb@yahoo.fr (H. Sambou)
}

\section{To cite this article:}

Hyacinthe. Sambou, Bienvenu. Sambou, Amadou. Tahirou. Diaw, Cheikh. Mbow, Vieux. Boukhaly. Traore. Remote Sensing Mapping of the Rice Field and Vegetal Cover and the Impacts of Soil Factors on Herbaceous in the Sub-Watershed of Boutolate (Lower Casamance, Senegal). American Journal of Environmental Protection. Vol. 3, No. 2, 2014, pp. 73-82. doi: 10.11648/j.ajep.20140302.16

\begin{abstract}
Rice cultivation in lowlands plays an important role for population livelihood in lower Casamance. This economic activity is known to be affected by many contraints which are climate change and soil salinity. soil salinity is observed in rice fields and in the vegetation cover of Boutolate sub-watershed which covers an area of 6594,21 ha. Due to this situation, anti-salt micro-dams were built to retain water and also changes in land use around the area. This work aims to study rice field area and vegetation cover dynamics in the sub-bassin area located in the south-western of Lower Casamance. An overall time period of 26 years was considered in our study. The satellite imagery Landsat TM of 1984 and 2003 and ETM+ of 2000 and 2010 combined with field ground data was used to analyze the rice field area, vegetation cover dynamics and to understand the impacts of climatic and anthropogenic factors on its evolution. Floristic inventory was also done using plot size $3 \times 3 \mathrm{~m}$ along the upstream and downstream of micro-dams. In each plot, soil samples were taken for laboratory analysis to determine the impacts of geological factors on herbaceous strata in cultivable paddy area. The results showed a decrease of area paddy during these periods. The decrease in cultivated area was due to rainfall deficit which increased soil salinity and the worse management and monitoring plan after micro-dams were established in 2004. These caused floods which affected 0,93\% of upstream rice-growing units in 2010 . The increase of shrub-tree savannah between 1984 and 2010 was due to the natural regeneration. The natural regeneration was favored by the decrease of fraudulent logging related to insecurity in the area and the expansion of fruit trees, particularly Anacardium occidentale. Anacardium occidentale area increased between 2000 and 2010. The soil physical parameters influenced significantly on density and diversity of herbaceous.
\end{abstract}

Keywords: Lower Casamance, Micro-Dams, Vegetation Cover, Rice Field, Satellite Imagery, Supervised Classification, Geological Parameters, Land Use

\section{Introduction}

Lower Casamance area has a very old tradition of rice growing [1]. It is located in south of Senegal in Ziguinchor province (region) and covers an area of 7,339km2 (Figure 1). At climatic level, Casamance belongs to coastal south Sudanese domain [2], what, because of this position, makes it be one of the rainiest zones in Senegal. It is covered with many waterways and valleys (Casamance River and its tributaries) with surface and underground-flowing which favors putting these depressions on cultivation. Lower Casamance is bound by soil-salinity phenomena, aggravated 
by climatic variability, marked, since 1968 , by significant drop in rainfall, and alteration of hydrous condition and flow reduction of Casamance River and its tributaries too [3] and [4]. Some of its valleys are otherwise characterized, in their working, by deep sea water invasion through lands due to low slopes. In Lower Casamance, rice growing is only during rainy season. As for family economy, trading exchanges, and traditional rites, rice holds a central position there. Farming, main incomes and food for population, is affected of it. Therefore, water command, perceived as strategy to secure rice production, find expression in equipment of small hydro-agricultural works of traditional design.

Micro-hydraulic dams works aim is to make profitable some of the valleys affected by soil-salinity and rainfall deficit, in order to increase rice production. Impacts of rainfall shortage on natural area have been variously studied. That is the way it is of mangrove deterioration [5], chemical and physical evolution of soils [6, 7-8,9], alteration of hydrological rate and chemical quality of Casamance River and its tributaries waters [10], decrease of food resources of animal and crops nature [11,12-13] and, development of societies [14].

Furthermore, erection of modern salt preventer micro-dams is here known since only these two last decades. The increase in the number of these kinds of works accentuates change in soil occupation, subject of few studies in the area. This thematic become a must in most of cartographic inventories and follow-up to environmental phenomena [15]. And that is because planning and follow-up to rice-growing spaces constitute a permanent concern for participants involved in water resources management, that we have undertaken the study of Boutolate sub-watershed side, characterized by prevalence of rice growing (more than 85\%) (Figure 1). This main activity is influenced by climatic hazards which lead to considerable changes. Remote detection is the appropriate tool to grasp spatiotemporal of soil occupation [16]. Availability of Land sat satellite images give an opportunity to characterize soil evolution of this sub-watershed side. However, the strong dependence of spectral characteristics is one of the main reasons of lack of reliability of the classified map [17]. To remove this peculiar constraint to remote detection, we based on field data to enhance classification accuracy and reliability of soil occupation maps got from 1984; 1992; 2000; and 2010 Land sat data.

Studied area deals with Boutolate sub-watershed side (Figure. 1), located between latitudes 12 $40^{\prime} 0^{\prime \prime}$ and $12^{\circ} 46^{\prime} 30^{\prime \prime}$ North and, between longitudes $16^{\circ} 7^{\prime} 0$ ' and $16^{\circ} 12^{\prime} 30^{\prime}$ "West, in Koubalan Rural Community, Bignona Department. This sub-watershed is covered with many valleys. It pertains to Baiila basin side backwater with slope of $0.0125 \%$. Its filling is dated back to 2004 with aim to favor intensification of rice growing by rice paddy racks salt-removing.

\section{Material and Methods}

\subsection{Climatic Data}

The slope of Boutolate sub-basin is located in coastal sudanese climatic area. The climatic data used in our analysis were from Tenghory meteorological station located $12 \mathrm{~km}$ from our study area. The figure 2 shows two distinct periods of annual rainfall evolution. The period 1975-1990 is characterized by a rainfall deficit and 1991-2011 by an increase in annual rainfall accumulation.

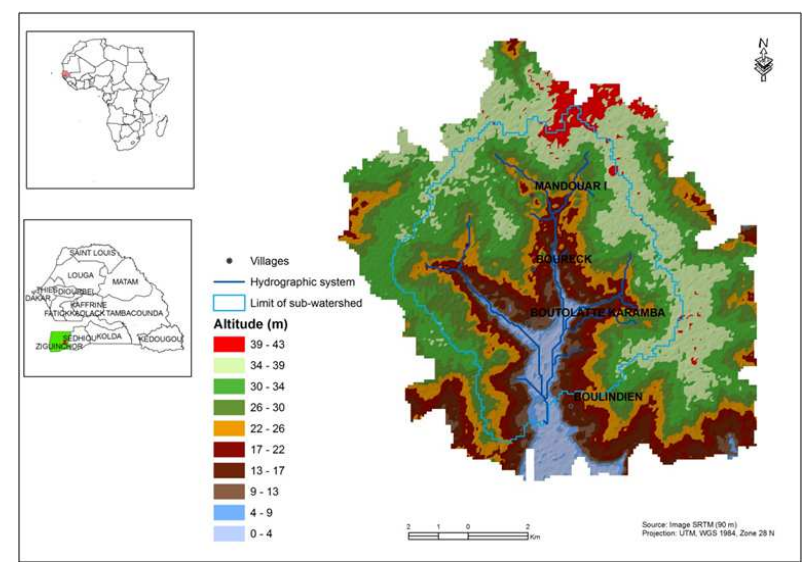

Figure 1. Location of Boutolate sub-watershed.

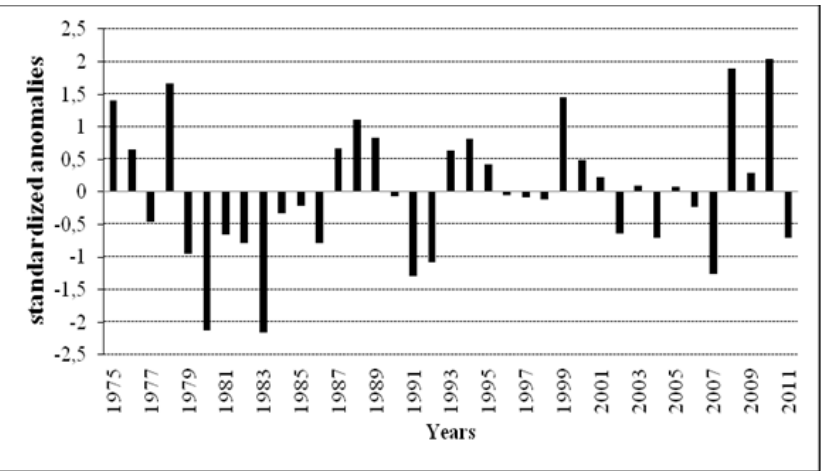

Figure 2. Standardized anomalies of annual rainfall at station Tenghory between $1975-2011$.

\subsection{Satellite Data Used}

The satellite imagery Landsat TM of 18/10/1984 and 16/10/1992 and ETM+ of 06/10/2000 and 28/12/2010 were used for the land use/cover mapping(Table1). The year 1984 was characterized by a drought while 2010 was marked by a slight resumption of normal rainfall.

To minimize the exaggeration associated with the herbaceous vegetation, a number of factors such as period were considered in the process of image selection. We determined late November and december to be the optimum time of year for image analysis. According [18], this period is characterized by a land cover related to woody vegetation. In addition, advantage of the dry season is to have low cloud cover. The satellite images used were downloaded in the United State Geological Survey (USGS) Landsat Earth Resources Observation Systems (EROS) Data Center. The 
field observations on the vegetation types and the cultivated area were carried out on February 2012. Secondary data such as GPS waypoints, topographical map (scale :1/50000) and interviews with rice-growers were obtained by the fieldwork carried out from november to june 2012. Training area were chosen in collaboration local farmers considering the homogeneous units, the land cover and the vegetation cover. GPS waypoints were used as landmark. Using multidates image required atmospheric correction, band calibrations which were used for this purpose.

Images processing, including its calibration, carrying colorful compositions and supervised classification was based on the performance of ENVI software while land use maps and changes were made by ArcGIS software.

Table 1. Satellite data used.

\begin{tabular}{ccccc}
\hline Data & Date of acquisition & Spectral Range $(\mu m)$ & $\begin{array}{c}\text { Nominal Spectral } \\
\text { Location }\end{array}$ & Resolution(m) \\
\hline ETM $^{+}$ & $06 / 11 / 2000$ & $1 .[0.45-0.51]$ & Blue & $30 * 30$ \\
& $28 / 12 / 2010$ & $2 .[0.52-0.60]$ & Green & $30 * 30$ \\
& & $3 .[0.63-0.69]$ & Red & $30 * 30$ \\
& & $4 .[0.75-0.90]$ & Near-IR & $30 * 30$ \\
& & $5 .[1.55-1.75]$ & Mid-IR & $30 * 30$ \\
& & $6 .[10.40-12.50]$ & Thermal-IR & $30 * 60$ \\
& & $7 .[2.09-2.35]$ & Mid-IR & $30 * 30$ \\
& & $8 .[0.52-0.90]$ & Panchromatic & $15 * 15$ \\
& & $1 .[0.45-0.52]$ & Blue & $30 * 30$ \\
& & $2 .[0.52-0.60]$ & Green & $30 * 30$ \\
& $18 / 11 / 1984$ & $3 .[0.63-0.69]$ & Red & $30 * 30$ \\
& $16 / 11 / 1992$ & $4 .[0.76-0.90]$ & Near-IR & $30 * 30$ \\
& & $5 .[1.55-1.75]$ & Mid-IR & $30 * 30$ \\
& & $6 .[10.20-12.50]$ & Thermal-IR & $120 * 120$ \\
& & $7 .[2.08-2.35]$ & Mid-IR & $30 * 30$ \\
\hline
\end{tabular}

To analysis the impact of physical soil parameters such as soil $\mathrm{Ph}$, salinity and conductivity bases on the herbaceous, an inventory was conducted. It was a random inventory using plot size $3 \times 3 \mathrm{~m}$. it was carried out in the lower downstream of the valley and the micro-dams. This lower part is where the rice is mainly cultived with the most productive rice paddies. Within each plot, soil samples were taken at the twenty five centimeters of the soil layer with a hand auger. The first soil layer is the effective depth of most of the grass and the place of salts accumulation.

\section{Image Processing}

Using multidates image required atmospheric correction according [19] and [20]. The images were georeferenced and band calibrations was performed.

However, no geometric correction was performed on all images used. To avoid gap due to the difference of Landsat sensor and optimize image superimposition for diachronic analysis, data from 1984, 1992 and 2000 were georectified with 2010 image taken from reference points bitter identified on the topographic map. Root-mean-square (RMS) error was 0,124 and less than a Landsat pixel. To detect changes, a supervised classification by maximum likelihood was performed because of the heterogeneity of the land elements in the sub-basin and several combinations were tested with bands 2, 3, 4, 5 and 7. The combination of bands 3-4-5 displayed respectively red, green and blue, highly recommended by [21] for the study of plant cover, allowed us to identify the major types of vegetation and other strata.
But the contrast obtained with this combination did not facilitate the exercise of the farmers in the choice of training plots. Finally, the bands 5-4-3 in RGB mode were selected because of the colors close enough to stained nature easily observable on the field. To homogenize the classification results, the images were filtered with a majority analysis using a filter of $3 \times 3$ pixels. Field data were used to improve the classification accuracy and reliability of the resulting maps. So, the training plots selected in the field with farmers were used to test the reliability. The methodology is summarized in Figure 4. All these operations were carried out in the same area for all scenes.

36 soil samples were taken to Laboratory d'Ecology Microbienne des Sols and Sols Systems Tropicaux (LEMSAT) and Laboratory des Moyens Analytiques (LAMA) for the soil parameter analysis. These two laboratories of Institute of Research pour le Development (IRD) which are certified ISO 9001 ensure scientifically useful results. Thus, various chemical analyzes were carried out using strict protocols.

\section{Cartographic Analysis}

The results based on supervised classification by maximum likelihood were exported in vector format with the Arc GIS software for the completion of the mapping process. Nine classes of land represented by habitation, saline waterway, fields of millet / peanut, dense dry forest, palm grove, Paddy not flooded, flooded paddy, shrub-trees-savannah and Muddy wetland were identified 
with statistics on the area Table 2.

Table 2. Evolution units of land sub-watershed of Boutolate.

\begin{tabular}{|c|c|c|c|c|c|c|c|c|}
\hline \multirow[b]{2}{*}{ Type of land cover } & \multicolumn{8}{|c|}{ Areas } \\
\hline & $\begin{array}{c}1984 \\
\text { hectares }\end{array}$ & $\%$ & $\begin{array}{c}1992 \\
\text { hectares }\end{array}$ & $\%$ & $\begin{array}{c}2000 \\
\text { hectares }\end{array}$ & $\%$ & $\begin{array}{c}2010 \\
\text { hectares }\end{array}$ & $\%$ \\
\hline Habitation & 62,91 & 0,96 & 67,12 & 1,02 & 68,87 & 1,04 & 72,46 & 1,10 \\
\hline Salina waterway & 93,31 & 1,41 & 121,67 & 1,84 & 128,43 & 1,95 & 80,95 & 1,23 \\
\hline Fields of millet/peanut & 991,22 & 15,03 & 1027,07 & 15,57 & 1011,03 & 15,33 & 724,94 & 11,00 \\
\hline Dense dry forest & 1279,05 & 19,40 & 1239,00 & 18,79 & 1145,05 & 17,37 & 1415,70 & 21,47 \\
\hline Palm grove & 285,28 & 4,33 & 149,70 & 2,27 & 148,60 & 2,26 & 219,90 & 3,33 \\
\hline Paddy not flooded & 370,47 & 5,62 & 368,54 & 5,60 & 351,81 & 5,33 & 296,24 & 4,49 \\
\hline Flooded paddy & & & & & & & 61,65 & 0,93 \\
\hline Shrub-trees-savannah & 3429,81 & 52,01 & 3589,08 & 54,43 & 3707,33 & 56,22 & 3631,91 & 55,08 \\
\hline Muddy wetland & 82,16 & 1,24 & 32,03 & 0,48 & 33,09 & 0,50 & 90,46 & 1,37 \\
\hline total & 6594,21 & 100 & 6594,21 & 100 & 6594,21 & 100 & 6594,21 & 100 \\
\hline
\end{tabular}

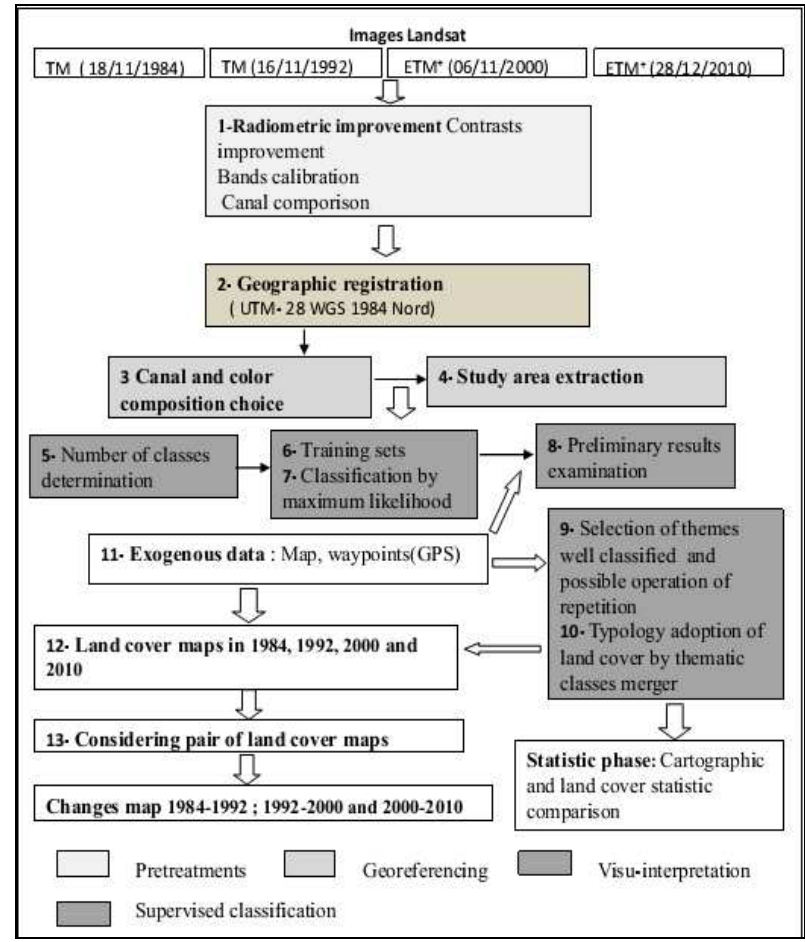

Figure 3. Synthesis of satellite data processing.

Crossing cards helped highlight the changes of land use of Boutolate sub-watershed between 1984-1992, 1992-2000 and 2000-2010 with conversions and modifications noted during these periods.

The validation of results obtained by supervised classification of land cover classes was performed with the most recent image (2010). The purpose of this operation is to check the quality of the results obtained in order to assess the risk of possible confusion and capabilities to better differentiate land cover units. The reference source for the validation is a set of data collected with GPS on site. The reference source for the validation is a set of data recorded with GPS on site. Two hundred points have been identified and their distribution among the land use classes depends on the extent of the area and the difficulty of detecting each class. Easy to identify classes were not taken into account. They include Saline waterway and Flooded paddy. The accuracy obtained by calculating the confusion matrix is equal to $89 \%$ with a Kappa coefficient equal to 0.86 for 2010 taken as reference.

\subsection{State of Land Use in 1984}

With 4994.14 hectares in 1984 (Table 2), the vegetation cover represents $75.73 \%$ of the area mapped. It is composed of wooded and Shrub-trees-savannah (3,429.81 hectares), dense dry forest (1279.05 hectares) and a palm grove (285.28 hectares). Fields of millet / peanut occupy 991.22 hectares or $15.03 \%$ of the area of the sub-watershed. The exposed paddy not flooded covers vegetation 370.47 hectares. Habitation and muddy wetland cover respectively 62.91 and 82.16 hectares (Figure $5 \mathrm{~A}$ ).

\subsection{State Land Use in 1992}

Shrub-trees-savannah is the most common type of land use. It occupies the largest soil area with (3589.08 hectares), $54,42 \%$ of the entire sub-watershed and an increase of nearly $32 \%$ (Figure $5 \mathrm{~B}$ ). This situation is the result of a renewed rainfall compared to 1984 . It is more important than the Dense dry forest (1239 hectares) which experienced a decline of nearly 40 hectares. Statistics un watered rice are almost steady between 1984 and 1992. Fields of millet / peanut have increased compared with the period 1984 (1027.07 hectares) or $0.5 \%$ of the total area of the sub basin. The palm grove is reduced $-2.06 \%$ and the surface are no more than 149.7 hectares (Figure 4).

\subsection{State Land Use in 2000}

As shown in Figure 5 C, in 2000 the areas of vegetation covering 1011.03 hectares for dense dry forest (17.37\%) and 1,707.33 hectares for wood and shrub savannah in trees $(56.22 \%)$ and 148.6 hectares for palm grove $(2.26 \%)$. The decline in palm grove result of increased salinization of the valley. The Paddy not flooded have shrunk of 16.73 hectares. Fields of millet / peanut acreage decreased slightly $(-0.2 \%)$ compared to 1992 (Figure 4).

\subsection{State Land Use in 2010}

Fields of millet / peanut significantly decreased in area, 
724.94 hectares in 2010 compared to 1011.03 hectares in 2000 a reduction of $-4.33 \%$ (Figure 5 D). Dense dry forest has increased by $4.10 \%$. Similarly, the palm grove has experienced an increase of $1.07 \%$. By against the shrub-trees-savannah is bush land shrank. She went from 3707.00 hectares in 2000 to 1631.91 hectares $(-1.14 \%)$ loss. The Paddy not flooded occupy only 296.24 hectares or $4.49 \%$ of the entire sub-watershed (Figure 4). The appearance of flooded paddy in 2010 reflects a positive impact of the establishment of structures for water retention.

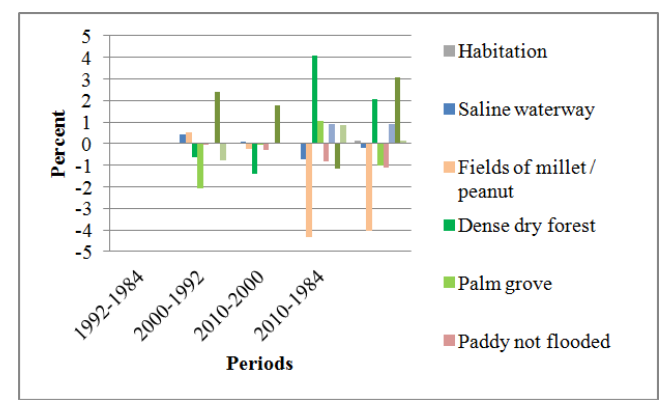

Figure 4. Evolution of land use in the sub-watershed of Boutolate.

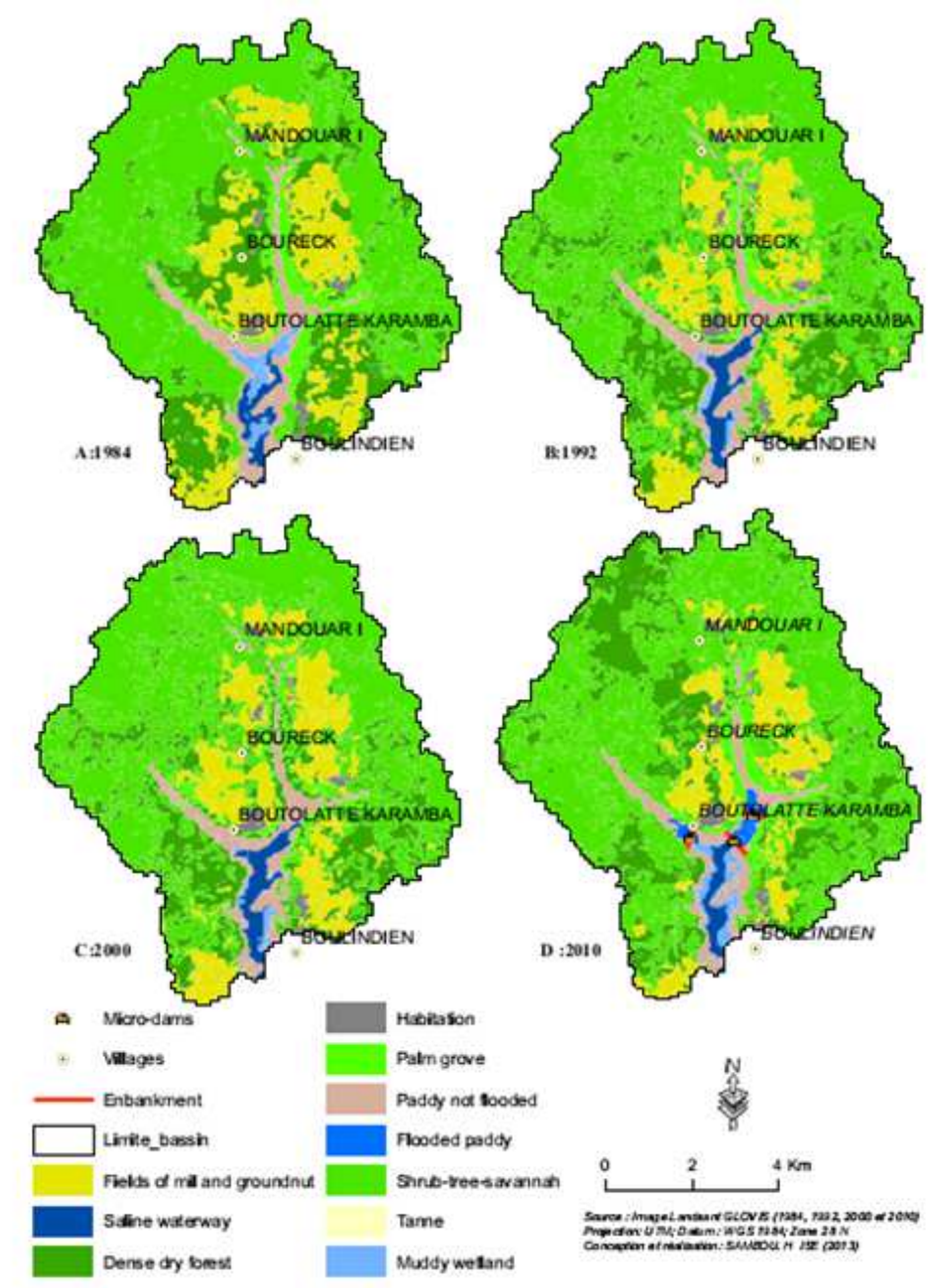

Figure 5. Land use in the sub-watershed of Boutolate in 1984 (A) 1992 (B) 2000 (C) 2010 (D).

\section{Analysis of Changes in Land Use in the Boutolate's Sub Watershed}

The study of the evolution of land use classes is based on three scenarios. These are the "mutations" and "conversions" of these units who oppose to "stability" case. By "mutation" we are suppose to perceive the changes within the same category of land use such as shrub-trees-savannah move to be a dense dry forest or vice versa. While the "Conversion" is the transition from one category to another, such as unaltered paddy not flooded that become shrub-trees-savannah. In deed "stability" refers to all classes that have kept their same characteristics during the four dates of our study, Specially none of them has not been affected by the changes, or conversions.

Cards changes result from crossing of two maps of land use in the sub-watershed (Figure 6A, 6B and 6C). The statistics of different changes are determined from maps of transfer. Each geographic entity (paddy not flooded, fields of millet / peanut, dense dry forest, shrub-trees-savannah, etc..). The habitation class was occupied unit of the least disturbed ground between these dates. Changing $18 \%$ of the palm grove in shrub-trees-savannah between 1984 and 
1992 could be related to rainfall deficit observed in the area from the 1980's with taking into account the water requirements of the species Elaeis guineensis.

In addition, the conversion of dense dry forest to Shrub-trees-savannah but also the inverse change is represent upon fairly large areas between 1984 and 1992 (Figure 6 A). Nearly 481.78 hectares spend of the dense dry forest to shrub-trees-savannah. This case is mainly observed in the west and south of the sub-watershed where relatively large areas are being degraded. However, densification of the shrub-trees-savannah is observed in some place mainly along the rivers. Among the many possible reasons able to explain densification of shrub-trees-savannah we have degradation dense dry forest linked to the highly exploitation of timber for household needs but also for the marketing of charcoal, but also and especially in developing the arboriculture on the slopes and uplands instead of rice crops. Indeed, farmers invest systematically in planting fruit species particularly Anacardium occidentale. Picking fruit and nuts Anacardium occidentale, allows producers to acquire income that often push them away from any want during the season. These incomes can thus be used to purchase food or material goods. Really flourishing in the area, nowadays arboriculture is a mainstay of the rural economy. establishment of plantations are increasing over the years like Boutolate almost every family has at least one Anacardium occidentale plantation.

In addition, approximately 597.47 hectares ( $17.2 \%$ ) increased from shrub-trees-savannah to dense dry forest from 1984 to 1992 . This can be explained by a decline in timber-related insecurity in the region, which is worse is from 1990. Therefore, the vegetation is denser in the corridors of areas that were once well sought by illegal forest operators. This situation remained until 2000. This case also justifies the slight change on the dense dry forest in shrub-trees-savannah between 1992 and 2000 (Figure 6 B) with only 160.22 hectares or $12.9 \%$ compared to the period 1984-1992. Furthermore, the stability of vegetation observed in the area between 2000 and 2010 (Figure 6 C), is due to the fact that from 2004 to 2005, youth from surrounding communities, supporting evil exploitation of forests and savannahs by foreign people have decided collaboration with the Water and Forest agents to engage themselves in the management of forest resources on their land. The forest is now divided into plots and operation now takes place by rotation system.

Conversions are across sub-watershed relatively low compared to changes and are diverse proportions. They unequally affect all land use systems with a predominance fields of millet / peanut (26.1\% conversion ) during the period from 1984 to 1992 corresponding to 259.19 hectares, or 33.7\% in 2000-2010 over 263 hectares (Figure 6 A and 6 C ). We note in this connection that, among all the 522.19 hectares converted more than $25 \%$ area was colonized by the shrub-trees-savannah. The practice of fallow which adds significant improvement in rainfall since the 2000s contributed significantly to the regeneration of vegetation in fallow fields in parts of sub-watershed. In addition, the consequences of different previous droughts (1980) causing soil salinization and acidification could explain the decline of rice crop in the giving way to shrub-trees-savannah. The conversion were also touched mudflats (36.7\%) from 1992 to 2000 with an area of over 11 hectares, $34.2 \%$ are converted into streams (Figure 6 B). Between 2000-2010; 13, $1 \%$ muddy wetland are converted under saline waterway and despite the development of micro-dams places. Since these years of study, the amount of land area rice crop did stop declining despite the development of the anti-salt and water retention structures dyke several hectares remain unusable. The facts outlined are enough to have not yielded the desired results such as rice intensification. This is due to the establishment of structures that are not built on the low flow channel valleys to allow proper drainage of rainwater which often promotes flooding rice plants for a long time under heavy rains. To this is added the mismanagement has been the subject of development works in the area because of financial problems related to the economic difficulties of the villagers who are struggling to honor their contribution, but also because of the impact of infrastructures that, for the effective desalinization sub-watershed is only slightly visible.

The inventories of herbaceous species has identified 42 species in 19 families. the family Poaceae monitoring that is dominant with Cyperaceous respectively 9 and 12 species. However, Eleocharis mutata is the dominant species.

According to the farmers interviewed, Eleocharis mutata colonize brackish or even salt. Its proliferation has been observed since the introduction of anti-salt micro-dams having helped store water upstream of the valley for a period of the year and the sedimentation of nutrients likely to be favorable to its development. Moreover, the variation of the volume of water strongly influences its expansion. Further study could help to better understand its expansion.
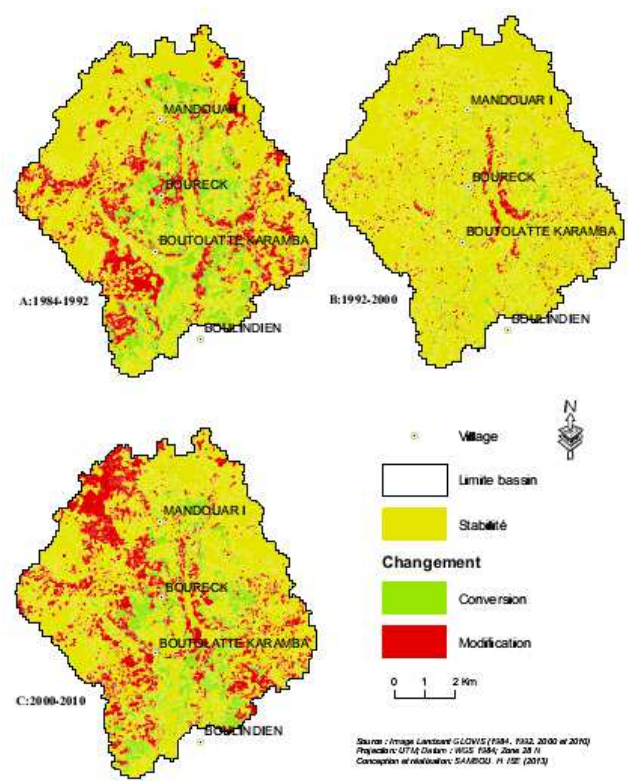

Figure 6. Map of changes in land use between 1984 to 1992 (A) 1992-2000 (B) 2000-2010 (C) in the sub-watershed of Boutolate. 


\section{Analysis of the Impacts of Soil Physical Parameters on the Density and Diversity of Herbaceous Plant Species}

The values of the chemical parameters of the soil are analyzed in the laboratory are recorded in Table 5. Among the measured chemical parameters, only $\mathrm{pHKCl}$ and salinity have a significantly effect on herbaceous (grasses) diversity $(\mathrm{P}<0,05)$ (Table 3).

Table 3. Multiple linear regression between diversity herbaceous according pHKCl species and salinity.

\begin{tabular}{ccccc}
\hline Coefficient & Estimate & s.e & t value & P. value \\
\hline Intercept & 1,6323 & 2,6447 & 0,617 & 0,537915 \\
$\mathrm{Ph} \mathrm{KCl}$ & 2,8172 & 0,7069 & 3,985 & $9,84 \mathrm{e}-05$ *** \\
Salinity & $-0,4556$ & 0,1273 & $-3,578$ & $0,000446 * * *$ \\
\hline
\end{tabular}

However, only $34 \%$ of species diversity variation is explained by the two explanatory variables.

That means there are others explanatory variables to be considered in the analysis. Similarly, the salinity and $\mathrm{pHKCl}$ also significantly influence the density of herbaceous species (p.value <0.05) with a much larger effect for $\mathrm{pHKCl}$ (Table 4) with an $\mathrm{r} 2=0.31$. These results show that the salinity $\mathrm{pHKCl}$ and can strongly influence the growth of non-tolerant varieties of rice.

Table 4. Régression linéaire multiple sur la densité des herbacées en fonction du $\mathrm{pH} \mathrm{Cl}$ et de la salinité.

\begin{tabular}{ccccc}
\hline Coefficient & Estimate & s.e & t value & P. value \\
\hline Intercept & $-0,9036$ & 2,5138 & $-0,359$ & 0,719688 \\
Ph KCl & 2,4810 & 0,6719 & 3,693 & $0,000296 * * *$ \\
Salinity & $-0,3704$ & 0,1210 & $-3,061$ & $0,002549 * *$ \\
\hline
\end{tabular}

Table 5. Soil parameters determined.

\begin{tabular}{|c|c|c|c|c|c|c|c|}
\hline Plots & Density & Dominance & Diversity & $\begin{array}{l}\text { Conductivity } \\
\mu \mathrm{S} / \mathrm{cm} \text { à } 25^{\circ} \mathrm{C}\end{array}$ & $\begin{array}{c}\text { pH } \\
\text { H2O } \\
\end{array}$ & $\begin{array}{c}\mathrm{pH} \\
\mathrm{KCl} \\
\end{array}$ & $\begin{array}{c}\text { Salinity } \\
\% 0 \\
\end{array}$ \\
\hline 1 & 9.77 & 22.91 & 20 & 32.8 & 4.81 & 3.85 & 0.0 \\
\hline 2 & 9.44 & 51.51 & 7 & 83.3 & 4.43 & 3.65 & 0.0 \\
\hline 3 & 10.11 & 21.05 & 11 & 135.5 & 4.04 & 3.72 & 0.0 \\
\hline 4 & 12.77 & 20.68 & 21 & 45.9 & 4.54 & 3.88 & 0.1 \\
\hline 5 & 7.00 & 33.33 & 10 & 608 & 3.37 & 3.43 & 0.1 \\
\hline 6 & 12.77 & 19.29 & 18 & 86.5 & 4.68 & 3.83 & 0.3 \\
\hline 7 & 3.33 & 50.00 & 8 & 487 & 3.37 & 3.34 & 0.0 \\
\hline 8 & 6.33 & 26.08 & 11 & 121 & 4.12 & 3.53 & 0.2 \\
\hline 9 & 3.00 & 38.7 & 6 & 12090 & 3.65 & 3.44 & 3.6 \\
\hline 10 & 4.33 & 41.1 & 10 & 11730 & 4.08 & 3.87 & 6.9 \\
\hline 11 & 4.88 & 30.76 & 7 & 8470 & 4.29 & 4.10 & 6.7 \\
\hline 12 & 3.66 & 19.14 & 4 & 13880 & 4.47 & 4.29 & 4.7 \\
\hline 13 & 5.11 & 38.46 & 9 & 10350 & 4.99 & 4.76 & 8.0 \\
\hline 14 & 11.00 & 23.37 & 13 & 20410 & 4.32 & 4.19 & 5.8 \\
\hline 15 & 3.22 & 30.00 & 4 & 14010 & 3.76 & 3.68 & 12.2 \\
\hline 16 & 4.11 & 28.37 & 7 & 21280 & 3.76 & 3.54 & 8.1 \\
\hline 17 & 6.00 & 16.66 & 8 & 5240 & 3.87 & 3.44 & 12.8 \\
\hline 18 & 2.22 & 42.85 & 3 & 1854 & 3.69 & 3.39 & 2.8 \\
\hline 19 & 4.00 & 37.50 & 11 & 1122 & 3.59 & 3.51 & 0.9 \\
\hline 20 & 5.55 & 40.00 & 7 & 835 & 3.44 & 3.36 & 0.6 \\
\hline 21 & 7.33 & 33.33 & 9 & 886 & 3.80 & 3.59 & 0.4 \\
\hline
\end{tabular}

\begin{tabular}{cccccccc}
\hline Plots & Density & Dominance & Diversity & $\begin{array}{c}\text { Conductivity } \\
\boldsymbol{\mu S} / \mathbf{c m}_{\mathbf{~ a ̀ ~ 2 5}} \mathbf{C}^{\circ}\end{array}$ & $\begin{array}{c}\mathbf{p H} \\
\mathbf{H 2 O}\end{array}$ & $\begin{array}{c}\mathbf{\text { KCl}} \\
\text { Salinity }\end{array}$ \\
\hline 22 & 3.66 & 30.00 & 9 & 1245 & 3.69 & 3.64 & 0.4 \\
23 & 6.11 & 42.85 & 10 & 776 & 3.29 & 3.27 & 0.6 \\
24 & 6.55 & 38.46 & 10 & 924 & 4.01 & 3.66 & 0.4 \\
25 & 4.33 & 28.57 & 11 & 2868 & 3.81 & 3.55 & 0.7 \\
26 & 5.33 & 63.63 & 8 & 1653 & 3.57 & 3.31 & 1.5 \\
27 & 5.66 & 36.36 & 9 & 756 & 4.08 & 3.51 & 0.2 \\
28 & 8.77 & 25.00 & 17 & 697 & 4.53 & 4.39 & 0.1 \\
29 & 11.33 & 23.72 & 18 & 1432 & 4.37 & 4.12 & 0.3 \\
30 & 10.00 & 31.57 & 15 & 1239 & 3.64 & 3.43 & 0.1 \\
31 & 8.40 & 28.12 & 12 & 874 & 4.36 & 3.82 & 0.0 \\
32 & 5.12 & 18.52 & 8 & 1041 & 3.94 & 3.68 & 0.0 \\
33 & 9.04 & 20.14 & 14 & 744 & 3.96 & 3.54 & 0.0 \\
34 & 7.14 & 16.22 & 6 & 1260 & 4.88 & 4.12 & 0.0 \\
35 & 4.94 & 14.02 & 8 & 958 & 4.72 & 4.06 & 0.0 \\
36 & 6.18 & 12.84 & 4 & 1124 & 4.68 & 3.98 & 0.0 \\
\hline
\end{tabular}

\section{Discussion}

Boutolate Sub-watershed has a relatively dense recovery rates $(30$ and $75 \%)$. The value of kappa, 0.87 for 2010 reflects, in view of the scale [22], the reliability of the classifications made. In this respect, consideration of the results of the class matrix class broadly confirms the bit of confusion in the four images. Two reasons for this: (i) the choice of classes based on radiometric values and the choice of training plots, (ii) field data and knowledge of the study area have facilitated the analysis and visual interpretation of images. However, few cases of confusion between classes (paddy not flooded, and habitation) are noted. This is explained by the fact that areas are stripped crop after harvest and therefore their reflectance is almost similar to that of habitation. Resolution Landsat $(30 \mathrm{~m})$ could also have an influence on the classification accuracy of small areas [23]. The analysis of the dynamics of change shows a notable decrease in rice area between 1984 and 2010, approximately 74.23 hectares. Indeed, in the 1980s, rainfall conditions have deteriorated in Lower Casamance. Major droughts of 1968, 1972, 1983 and 1984 have left traces in the collective memory of the people of the region . The most visible signs of degradation were the water deficit has led to salinization and acidification of rice field with the consequent abandonment of some rice paddies .

Face resulting from climate degradation effects, farmers in Lower Casamance have already responded through involving in adaptation strategies, including developing technical management of water resources such as dams and dikes locally manufactured. The Government of Senegal to support the efforts of farmers implemented extensive programs of protection and recovery of abandoned land. It is, among other Society Agricultural Development of Casamance in 1973, the Integrated Agricultural Development Project in Casamance in 1974, the Autonomous Rural Development Project in Lower Casamance in 1988, the Project of Water Management in the southern area in 1989 and the Rural Development Support Project in Casamance in 2005. These projects all 
has the aim to establish irrigation schemes smaller (anti-salt retention and micro-dams) at the heart of some valleys. Boutolate sub-watershed of benefited from these types of hydro-agricultural works which are increasingly popular in various parts of the world marked by persistent droughts [24]. Thus, the appearance of flooded areas in 2000 and 2010 is one of the few positive impacts of micro-dams whose establishment dates back to 2004. However, one of the limits of micro-dams is related to the topography. Indeed, when the topography is not favorable enough, it becomes difficult to reconcile the rice fields located in the depths of those located in the slopes or plateaus. When the bins adjacent to the dam suffers from flooding the plot slopes suffers from a lack of water. This causes problems between lowland rice and those paying or trays. The former tend to open the valve to regulate the amount of water while the second are favorable to their closure. To solve this problem, the construction of intermediate dikes or so micro-dams cascade can help overcome this difficulty.

Another limitation of micro-dams is still insufficient in coordination of interventions and lack of monitoring mechanisms, but also weakness in resource's mobilization, technical failure and lack of accompanying measures initiatives. The creation of farmer organizations and strengthening their capacity for self-management is often overlooked by donors. To this is added agro-soil constraints. Deductions storing runoff constitute a settling tank. All the solid particles are deposited resulting in a gradual silting up of micro-dams. Siltation not promote migration of nutrients necessary for the development of rice. In addition, most of the micro-dams are located in the valleys already salinized and acids making it very difficult operation. Hydraulic water management plan is of great importance because they are poorly managed, water retention can become a salt marsh with a higher than this before micro-dam salinity. This is what could explain the high salinity of rice by location in the upstream part. The absence of the Management Committee and qualified in the management of micro-dams people is often noted.

Consequently, this situation does not foster the development of rice cultivation practiced with traditional rudimentary instruments; these although adapted to the culture of Muddy wetland soils remain very operational in the current conditions of worsening climate. Because of this, intensification of rice cultivation still remains a major concern for farmers. To circumvent this situation, farmers are opting for the use of improved or short cycle, row planting varieties and direct seeding even against the will of the customary chiefs yet submitted to the traditional conservative ideology [25]. Rice growing varieties with short cycle is often practiced on the trays and slopes after clearing the space into shrub-trees-savannah. Moreover, considering the dynamics of other land area classes, training in shrub-trees-savannah knows an increase from $52.01 \%$ to $55.08 \%$ between 1984 and 2010 . That situation would represent a forms of degradation of vegetation in the sub-watershed because the increase the area of this plant formation was carried out mostly working against of dense dry forest. This statement confirms the results obtained in the area in 2005 by the Ecological Monitoring Centre (CSE). Several factors may account the fluctuation of the vegetation, including the growing row of human activities and the frequency of rainfall deficits observed in the area between 1980 and 1987.

In addition, the increase in shrub-trees-savannah can be explained by the proliferation of large-scale plantations of Anacardium occidentale whose establishment has been encouraged by the Project "Senegalese-German Cashew (PASA)". Indeed, the project was settled towards 1980s in the region of Fatick (west-central part Senegal) with the goal to enhance research and development of cashew. In Lower Casamance the peasants, mistrustful of the effects that the species may have on soil quality were first realized plantations on small scales. It is only with the opening of the Indian market to marketing cashew nuts coming from Africa that planting of Anacardium occidentale has begun to expand over large areas. In Lower Casamance phenomenon experienced its expansion from 2000. The Anacardium sector plays an important economic role in the production areas in terms of income generation and job creation. In the region, men and women become active from March to July within small-scale processing of cashew nuts. Income from this activity encourage farmers to plant more, but also to protect the plantations. This phenomenon has then led to the increase of the area of scrub vegetation in the sub watershed of Boutolate between 2000 and 2010. The process of land use changes in the study area varies according to the class in question. The latter result confirms the findings [26] about the dynamics of vegetation, depending on each situation, the analysis of trends in relation to the status of the area, the type of training considered and interventions. The replenishment dynamic of dense dry forest between 2000 and 2010 to link with renewed rainfall recorded from 1988, but also with the socio-cultural sacred site forest function (website and organizing ceremonies traditional). Indeed, in Lower Casamance, tradition is commonly associated with the notion of sacred wood most dense dry forests in the sub-watershed maintaining the function of the sacred with the practices, customs enjoy strict protection.

The $30 \mathrm{~m}$ resolution Landsat data used may be a limitation in the spatial analysis of rice paddies. Moreover, they have proved very suitable for the study of the dynamics of vegetation.

The use of satellite images of high spatial resolution to further refine the results of the evolution of the rice area is another avenue to explore.

\section{Conclusion}

The location and the precise measurement of changes in land use are important for assessing the agrarian dynamics and understand the process that governs them. The research was intended to make the state of play and evaluate the 
dynamics of rice fields and vegetation cover in the Boutolate sub-watershed of from remote sensing tools. The diachronic study of land cover mapping between 1984 and 2010 highlighted some changes with an increase in shrub-trees savannah and a decline in rice fields.

The consequences of a rainfall shortage occasioning salinization contributed significantly to the gradual abandonment of agricultural practices. It is the same for the development of anti-micro dams salt which the dynamic change of water and dissolved components within the upstream soil. A seasonal pattern replaces the daily tides. A seasonal pattern overrides the daily tides pattern. This dynamic is characterized by concentration and acidification of soils during the prolonged exposure will phase. It also emerges from this study that the plant formations have recorded dynamic variables of a thematic class to another during this period. The most encouraging finding is the regeneration of the shrub savannah into wooded savannah during the same period. However, this overall positive evolution of this training must be shaded due to non-compliance with rules. The increased area of scrub vegetation into shrub-trees-savannah and significant decline in rice area, between the period 1984-2010, analyzed on Landsat images can evoke other problems. Indeed, the management of environmental policies in sub watersheds in the Lower Casamance, is influenced by anthropogenic impacts. Thus, the diachronic monitoring showed that more climatic deterioration, the media management factor which explains the extent of the degradation process. The success of anti-salt micro-dams can only be possible through the integration of rice farmers in making decisions about the management of their resources.

This study is a first step in the process of highlighting the state of development of the rice area in the sub watershed Boutolate. Beyond practicality, it also opens, research perspectives on the analysis of the evolution of rice fields, farmers' organizations interactions and climate impacts. To properly measure the magnitude of the impact of micro-dams on the rice cultivation, it should enlarge this study to other sub-watersheds in the landscaped area.

\section{Acknowledgements}

We thank the Project: West African Network for studies of environmental change (WANSEC) of DANIDA-FFU program, 21-08-KU and the Climate Change and Water Program (CCW) for the International Development Research Centre (IDRC) for financial and material support that enabled the completion of this work

\section{References}

[1] Pelissier , P., ( 1966). Farmers in Senegal . Agrarian civilizations Kayor the Casamance. Printing Fabrègue Saint Yrieix , France , 939 pages.J. Clerk Maxwell, A Treatise on Electricity and Magnetism, 3rd ed., vol. 2. Oxford: Clarendon, 1892, pp.68-73.
[2] Sagna , P., ( 2005 ) . Climate dynamics and recent developments in the western part of West Africa. Thesis status of Letters PhD . Department . Geography, Faculty of Humanities and Social Sciences / University of Cheikh Anta Diop . 786 pages.

[3] Dacosta, H. , (1989). Precipitation and runoff in the basin of the Casamance. 3rd cycle thesis , Faculty of Letters and Human Sciences, University Cheikh Anta Diop of Dakar, 278 pages .

[4] Sane, T. , (2003). Climate variability and its impacts on the environment and human activities in high - Casamance. Doctorate 3rd cycle . Department . Geography, Faculty of Humanities and Social Sciences / University of Cheikh Anta Diop . 366 pages .R. Nicole, "Title of paper with only first word capitalized," J. Name Stand. Abbrev., in press.

[5] Marius , C., Lucas , J. , Kalck, Y. , (1986 ) . Evolution of the Gulf of Casamance and Late Quaternary vegetation changes and mangrove soils related to the current drought. In Global Changes in Africa during the Quaternary, Paris , France, Office of Scientific and Technical Research Overseas ( ORSTOM), Works and documents, 197 , p. 293-295.

[6] Vieillefon , J. , (1977 ) . Soils of mangroves and salt flats of Lower Casamance ( Senegal ). Importance of the geochemical behavior of sulfur in their pedogenesis . Paris , France, Memory, 83, 292 p.

[7] Marius , C., ( 1985). Mangroves of Senegal and Gambia . Ecology . Soil Science. Geochemistry. Development and management. Paris , France , ORSTOM , Works and documents, 193, $368 \mathrm{p}$.

[8] Boivin , P., (1990 ) . Physical characterization of acid sulphate soils in the valley of Katouré (Lower Casamance , Senegal ). Study of spatial variability and relationships with soil characteristics . Paris , France , ORSTOM Office , Research and Thesis, 231 pages.

[9] Montoroi , J.P. , (1994) . The water dynamics and geochemistry salts Watershed Djiguinoum (Casamance , Senegal ). Impact on the sustainable management of mangrove ecosystems in times of drought. PhD thesis, University Henri Poincaré -Nancy I, France , 349 pages .

[10] SAOS , J.L. , Dacosta , H. , (1987 ) . Evolution hydrological watershed marginal- littoral : the backwater Bailla (Lower Casamance) . In: "Studies of estuaries and lagoons of Senegal " EPEEC UNESCO - 0.59-76

[11] Montoroi , J.P. , (1996) ). Sustainable land management of the mangrove ecosystem in Casamance ( Senegal). Dynamics of water and salts in times of drought. Thesis, ORSTOM , Paris , France, 263 pages.

[12] Cormier -Salem , M.C. , (1992 ). Contribution to the geographical study of aquatic areas: Casamance. Paris , France, ORSTOM , studies and thesis, 583 pages.

[13] Pages , J., ( 1992 ). Phytoplankton biomass and production of two systems paralic West Africa . Paris , France, ORSTOM, Works and microfiltration documents. , 82, 221 pages.

[14] Cheneau-Loquay, A. ( 1988). The relationship between space and energy in Casamance. Energy and space in Senegal , Bordeaux, France, CEGET -CNRS , works and documents of Tropical Geography , 62 , Volume 2, p.109 -243 . 
[15] Ouattara, T, Dubois, J. M. , Gwyn, J., (2006). A land cover mapping method in arid environment using multisource data and the TSAVI vegetation index, Remote Sensing, Vol. 6, No. 4, pp . 291-304.

[16] Lambin, E. , (1988) ). Contribution of satellite remote sensing to study land systems and land management in West Africa. Example in Burkina Faso. PhD thesis, Université Catholique de Louvain, 239 pages.

[17] Mahamane, A. ( 2006). Floristic studies , phyto- sociology and phytogeographical vegetation Parc Régional du W du Niger. Acta Bot Gallica 153 : 265-9.

[18] Mbow , C. Diaw, A.T. ( 2003). Choice of spectral indices for mapping vegetation in savannah environments. Africagis.

[19] Lamachère , J. M., Puech, C., (1996). Remote sensing , mapping of surface and hydrological modeling. In ORSTOM ( ed. ) Proceedings of the Workshop of the United Nations Food and Agriculture. Montpellier, 55 pages.

[20] Richter, R. (1997 ) Correction of atmospheric and topographic effects for high spatial resolution satellite imagery . International Journal of Remote Sens-ing, vol. 18 ,
No. 5 , p. 1099-1111

[21] Girard, M. C. , Girard , C., ( 1999). "Applied Remote Sensing, tropical and tropical zones " Dunod, Ed Paris, 529 pages.

[22] Landis, J. R., Koch, G.G. (1977). The measurement of observed agreement for categorical data. Biometric 33: $159-74$.

[23] Bamba, I., (2010). Anthropisation and spatio-temporal dynamics of forest landscapes in the Democratic Republic of Congo. PhD thesis, Free University of Brussels, 205 pages.

[24] Cecchi, P., (2007). Water sharing: Small dams of Côte d'Ivoire. Institute of Research for Development edition, 295 pages.

[25] Diédhiou, L., (2004). Rice, symbols and development in Lower Casamance Diola. Presses the University of Laval, 339 pages.

[26] Mbow, C., (2009). Potential and dynamics of carbon stocks and penny-Sudanese-Guinean savannas dano Senegal. $\mathrm{PhD}$ thesis of State, Institute of Environmental Sciences, Faculty of Science and Technology of the University Cheikh Anta Diop. 319 pages. 